\title{
Evaluation of acaricidal activity of different seed oils on Psoroptes cunniculi (Delafond, 1859) (Cheyletidae) in rabbits
}

\author{
Isaiah Oluwafemi Ademola ${ }^{1 *}$, Ibironke Adetolu Ajayi ${ }^{2}$,Vivian Nwakife \\ Aghanu $^{2}$, Chris Chuka Okonkwo ${ }^{2}$ \\ ${ }^{I}$ Department of Veterinary Microbiology and Parasitology, University of Ibadan, Ibadan, Nigeria \\ ${ }^{2}$ Industrial unit, Chemistry Department, Faculty of Science, University of Ibadan, Ibadan, Nigeria
}

\begin{abstract}
:
Context: Mange is one of the common animal diseases worldwide. Lack of tools to evaluate mange severity in animals and to demonstrate its importance has hindered the efforts of veterinarians to control the disease.

Objective: This study was design to evaluate the efficacy of oils from five plants against Psoroptes cuniculi in rabbits.

Materials and methods: Seed oils of Treculia africana Decne (Moraceae), Pentaclethra macroplylla Benth (Mimosidae), Calophyllum inophyllum Linnaeus (Calophyllaceae), Garcinia mangostana Linn (Guttiferae) and Monodora myristica Gaertn (Annonaceae) were extracted with hexane. Acaricidal activity of the plants and ivermectin was investigated in six groups (five per group) of rabbits naturally infested with psoroptic mites to determine their relative efficacy. Single dose of the oils were applied topically on the affected parts every morning for six weeks and skin scrapings collected weekly to determine mite number.

Results: Significant $(P<0.05)$ decrease in the number of mites (from 1.7 to 0.18 per $\mathrm{cm}^{2}$ ) was observed in $C$. inophyllum, which is the most active oil, six weeks post-treatment. Similarly C. inophyllum demonstrated the best activity (89.41\%) followed by G. mangostana (88.89\%), P. macrophylla (81.45\%), T. africana $(40.10 \%)$ and M. myristica (24.76\%). The weight gain of rabbits treated with oil of Calophyllum inophyllum was significantly higher than the rabbits treated with other seed oils and ivermectin. The mean recovery response of C. inophyllum seed oil was better than the other oils.
\end{abstract}

Discussion and conclusion: The results indicate that three of the seed oils could be useful alternatives to synthetic acaricides.

Key words: Acaricide, chemotherapy, ectoparasite, hexane extract, mange

\section{Introduction}

Mange is a skin disease of mammals caused by a tissue-burrowing arthropod, the mange mite. A variety of mange mites exist; the one most often identified as the cause of mange in Nigeria is Psoroptes cuniculi Delafond, (Cheyletidae). When mange is present in a large rabbit colony it becomes a serious menace unless adequate measures are taken to control it. The disease seems invariably to appear first on the nose, later spreading over the frontal region, lips, eyelids, and base of the ears. Simultaneously with the spread of lesions on the head, the lateral aspect of the hind limbs, the dorsal aspect of the fore limbs and the external genitalia are involved. In extreme cases, the skin of the abdomen is also affected.

Several arthropod reproductive inhibitors and repellents have been extracted from plants from ancient times. These extracts affect the feeding behavior and life cycle of parasites (Tooning et al., 1988; Green et al., 1991; Wells et al., 1993; Perich et al., 1995). As pesticides of synthetic origin may have a negative impact on the environment, and pest resistance to toxic chemicals can develop after repeated applications, the use of natural products has become more popular. For example, pyrethrins are insecticides derived from the chrysanthemum plant. They are common ingredients of parasite control products and are neurotoxic at high levels (Hansen et al., 1994). The most commonly used derivates of citrus fruits are D-limonene and orange essential oils. The main advantage of such products is a high margin of safety for warm-blooded organisms (Hooser et al., 1986). A herbal lotion commercially available as $\operatorname{Himex}^{\circledR}$ (containing extracts of Polyalthia longifolia cv. pendula (Annonaceae), Cedrus deodara (Roxb.) G. Don f (Pinaceae), wax, soap and distilled water) was found effective against Sarcoptes mange of goats and dogs (Tripathy et al., 1988) and sarcoptic mage of camels (Tripathy \& Acharjyor, 1990). Similarly Himex ${ }^{\circledR}$ was found to be effective against both sarcoptic and psoroptic mange of buffalo (Sharma et al., 1982; Rupra, 1980). The aqueous leaf extract of Tephrosia vogelii Hook (Leguminosae) has also been observed in Teso region of India to be use for the treatment of mange (Toyang et al., 1995). T. vogelii was reportedly used against mange, ticks and black quarter by the Fulani pastoralists, while the root and seeds are used against ticks on animals (Hutchings et al., 1996). 
Treculia africana Decne (Moraceae) was named after a French Botanist called Augustus Trecul. It has the following common names; African breadfruit, muzinda, mwaya and brebretin. Being an ever-green forest tree 10-50 $\mathrm{m}$ high and $3 \mathrm{~m}$ in girth, it has a dense spreading crown and fluted trunk. Pentaclethra macrophylla Benth (Mimosidae) (African oil bean tree) a large leguminous woody plant belonging to the sub family mimosidae has been cultivated in Nigeria since 1937. The plant grows to about $21 \mathrm{~m}$ in height and about $6 \mathrm{~m}$ in girth (Keay, 1989). Garcinia mangostana Gaertn (Annonaceae), commonly known as mangosteen is one of the most universally recognized tropical fruit. It is an evergreen tree that originates from South East Asia and is also seen in Nigeria. It can reach $6-25 \mathrm{~m}$ and has leathery leaves (Morton, 1987). The fruits are dark purple or reddish with a pleasant aroma (Jung et al., 2006) exuding from the white juicy edible pulp, which has high sugar content (Nakasone \& Paul, 1998). Mature fruits may be $6-7 \mathrm{~cm}$ in diameter and contain $5-7$ seeds. Monodora myristica Gaertn (Annonaceae) also known as African nutmeg is a tree of $35 \mathrm{~m}$ high and $2 \mathrm{~m}$ in girth. The fruit has a sweet smelling pulp with embedded seeds. The seed oil has been shown to contain both essential and fixed oil. Calophyllum inophyllum Linnaeus (Calophyllaceae) is a beautiful ornamental tree that occurs mainly in the tropics. The leaves are reported to contain tannin while the embryo that becomes large on maturity contains oil and resin. In this study, we investigated the acaricidal activity of five seed oils against P. cuniculi and their relative effects on rabbits.

\section{Oil extraction}

\section{Materials and method}

Samples of T. africana, P. macrophylla, C. inophyllum, G. mangostana and M. myristica seeds were collected from Ibadan, identified and authenticated by Prof. Ayodele A.E in the herbarium of the Department of Botany, University of Ibadan, Nigeria where voucher specimens were deposited with voucher numbers UIH22366, UIH-22364, UIH-22367, UIH-22365 and (UIH-22368), respectively. The seeds were pulverized and extracted with hexane using a Soxhlet extractor $\left(68{ }^{\circ} \mathrm{C}\right)$ for about $8 \mathrm{~h}$. The extracts were preserved in labeled dark glass bottles at room temperature until used.

\section{Experimental design}

Thirty-five rabbits naturally infected with P. cuniculi weighing approximately $1.2 \mathrm{~kg}$ were divided into seven groups (five per group with male and female). The rabbits were fed with pellet and water ad libitum. Skin scraping was obtained from each rabbit in all the groups before treatment and weekly after treatment with the oils and ivermectin. The oils were applied on the affected parts every morning for six weeks. Mange infested areas on the skin were scraped (per $\mathrm{cm}^{2}$ ) weekly into Petri-dishes with the blunt end of scalpel blade until blood start to ooze out. The scrapings were digested in $10 \% \mathrm{KOH}$ and mites were counted under the microscope. Animals were weighed and observed weekly for signs of healing using presence of lesions ( 0 ), disappearance of lesions (1), crust (2), scabs (3), and hair re-growth (4) as indices for scoring efficacy.

\section{Statistical analysis}

The results were analysed statistically using Student's t-test. The minimum level of significant was fixed at $\mathrm{p}<0.05$ and $95 \%$ confidence interval.

Percentage efficacy $=\frac{\mathrm{Nc}-\mathrm{Nt}}{\mathrm{Nc}} \times 100$

Where $\mathrm{Nt}=$ Number of mites after treatment of rabbits

$\mathrm{Nc}=$ Number of mites before treatment of rabbits

\section{Results}

All the tested plant products were lethal to the mites at different levels. The geometric mean of mites per $\mathrm{cm}^{2}$ decreased with time (Fig. 1). The number of mites significantly decreased (from 1.84 to $0.75 \mathrm{per}^{2}$ ) in scrapings from the group of rabbits treated with ivermectin 1 week post-treatment and greater improvement (from 1.84 to 0.23 per $\mathrm{cm}^{2}$ ) of rabbits was noticed two weeks post-treatment. Similarly significant decrease (from 1.7 to 0.42 per $\mathrm{cm}^{2}$ ) in the number of mites was observed four weeks post-treatment in the group of rabbits treated with $\mathrm{C}$. inophyllum which is the most active of the oils against the mites. Six weeks after treatment with oils of T. africana, and M. myristica the mites count were still high indicating poor acaricidal activity. The effectiveness of the seed oils of C. inophyllum, G. mangostana, P. macrophylla, T. africana, and M. myristica are illustrated in Figure 2. The oils of C. inophyllum and G. mangostana reduced the number of parasites by up to $89 \% 6$ weeks post treatment. Oils of T. africana, and M. myristica proved to be less effective (40.10 and 24.76\% respectively) against mites 6 weeks post-treatments. The weight gain of rabbits treated with oil of $\mathrm{C}$. inophyllum was significantly $(\mathrm{P}>0.5)$ higher than the rabbits in the groups treated the other oils and ivermectin (Fig. 3). The mean recovery responses of the rabbits treated with oils of C. inophyllum (4) was 
comparable to that of ivermectin (4) which showed the best response, followed by seed oils of P. macrophylla (3) and G. mangostana (3) while the seed oils of M. myristica (1) and T. africana (1) demonstrated the least recovery response (Table 1).

\section{Discussions}

The six seed oils tested were lethal to the mange mites although the activity differs with oil. Seed oil of C. inophyllum was the most active against psoroptic mange of rabbits. The oil reduced mite load, improved healing of lesions, and hair re-growth was faster compared to the recovery response of the other seed oils. The weight gain of the rabbits treated with this seed oil was significantly $(\mathrm{P}>0.5)$ higher than that of other seed oils and ivermectin. It is possible that the oil possess antibacterial property, which inhibited secondary bacterial infection hence the rabbits recovered from anorexia and ate the feed provided more than the rabbits treated with ivermectin and other seed oils. The efficacy of G. mangostana was comparable to that of C. inophyllum; however, the number of mites recovered from rabbits treated with G. mangostana was higher than those of the rabbits treated with C. inophyllum hence there could be a relapse if the mites are not totally killed. The recovery response and weight gain of the rabbits treated with $\mathrm{C}$. inophyllum was also better than those of the rabbits treated with G. mangostana. That could be the reason C. inophyllum is being widely used against mange infestation in India. The efficacy (about 81\%) and the mean number of mite recovered from rabbits treated with the seed oil of P. macrophylla is comparable. The seed oils of T. africana and M. myristica are not promising as acaricides because the efficacy of both oils and recovery response were poor. The weight gains of the rabbits treated with both oils were also poor and the mean mite number recovered from the rabbits was high 6 weeks post-treatment.

\section{Conclusion}

Vegetable oils have been shown to be potential medicine against various skin diseases. From five crude seed oils evaluated, three (C. inophyllum, G. mangostana, and P. macrophylla) have shown promising activity against psoroptic mange infestation in rabbits. Since rabbits are kept for different important purposes such as source of food (because of it low cholesterol content and high protein), wool, leather, laboratory animal for research as well as pet, it is important to further research on these seed oils as possible alternative remedies to synthetic acaricides against mange infestation.

\section{References}

[1]. Green MM, Singer JM, Sutherland DJ, Hibben CR (1991). Larvicidal activity of Tagetes minuta (marigold) toward Aedes aegypti. J Amer Mosq Control Ass, 7, 282-286

[2]. Hansen SR, Stemme KA, Villar D (1994). Pyrethrins and pyrethroids in dogs and cats. Comp Cont Ed Pract Vet, 16, 707-712

[3]. Hooser SB, Beasley VR, Everitt JI. (1986). Effects of an insecticidal dip containing D-limonene in the cat. J Am Vet Med Assoc, $189,905-908$

[4]. Hutchings A, Scott AH, Lewis G, Cunningham B., (1996). Zulu Medicinal plants. An Inventory. University of Natal Press. Scottsville 3209.

[5]. Jung HA, Su BN, Keller WJ, Mehta RC, Kinghora D. (2006). Antioxidant xanthones from pericarp of Garcinia mangostana (Mangosteen). J Agric Food Chem. 54, 2077-2082.

[6]. Keay RWJ. (1989). Nigerian trees. Claredon Press. UK, pp281

[7]. Morton J. (1987). Fruits from warm climates. Creative Resource system in Miami, USA. pp 304

[8]. Nakasone HY, Paul E. (1998). Tropical fruits. Wailly ford, U.K Cab International pp 445.

[9]. Perich MJ, Wells C, Bertsch W, Tredway KE. (1995). Isolation of the insecticidal components of Tagetes minuta (Compositae) against mosquito larvae and adults. J Am Mosq Control Ass, 11, 307-310

[10]. Rupra NS, Verma RK, Chhabra MB. (1980). Evaluation of some acaricides against psoroptic mange in buffaloes. Haryana Agric Univ J Res, 10, 309-313.

[11]. Sharma MC, Gupta OP, Pandey HS. (1982). Clinical trial of Himax ointment against mange in buffalo calves. Agric. Sci. Digest, 2, 124-131.

[12]. Tooning YC, Schooley DA, Bakert FC. (1988). Isolation of insect juvenile hormone III from a plant. Nature 333 (6169), 170-171

[13]. Toyang NJ, Nuwanykpa M, Ndi C, Django S, Kinyuy WC. (1995). Ethnoveterinary Medicine Practices in the Northwest Province of Cameroon. In: Indigenous Knowledge Development Monitor. 3(3) pp 20-22. Centre for International Research and Advisory Network (CIRAN).

[14]. Tripathy SB, Tripathy SN, Das PK. (1988). Studies on the therapeutic efficacy of Himax lotion on sarcoptic mange of goats and dogs. Pashudhan, 3(10), 4-10

[15]. Tripathy, SB, Acharjyor LN. (1990). Sarcoptic mange in camels and its treatment. Indian J Indg Med, 7, 21-26

[16]. Wells C, Bertsch W, Perich M. (1993). Insecticidal volatiles from the marigold plant (Genus tagetes). Effect of species and sample manipulation. Chromatographia, 35, 209-215

Table 1: Comparison of mean recovery response of the different oil applications

\begin{tabular}{llllllll}
\hline GROUPS & WEEKS & & & & & 5 & 6 \\
\cline { 2 - 7 } T. africana & 0 & 0 & 0 & 0 & 0 & 1 & 1 \\
P. macrophylla & 0 & 0 & 0 & 0 & 1 & 2 & 3 \\
C. inophyllum & 0 & 0 & 0 & 1 & 2 & 2 & 4
\end{tabular}




\begin{tabular}{llllllll} 
G. mangostana & 0 & 0 & 0 & 1 & 2 & 3 & 3 \\
M. myristica & 0 & 0 & 0 & 0 & 0 & 1 & 1 \\
Ivermectin & 0 & 0 & 1 & 2 & 3 & 4 & 5 \\
\hline
\end{tabular}

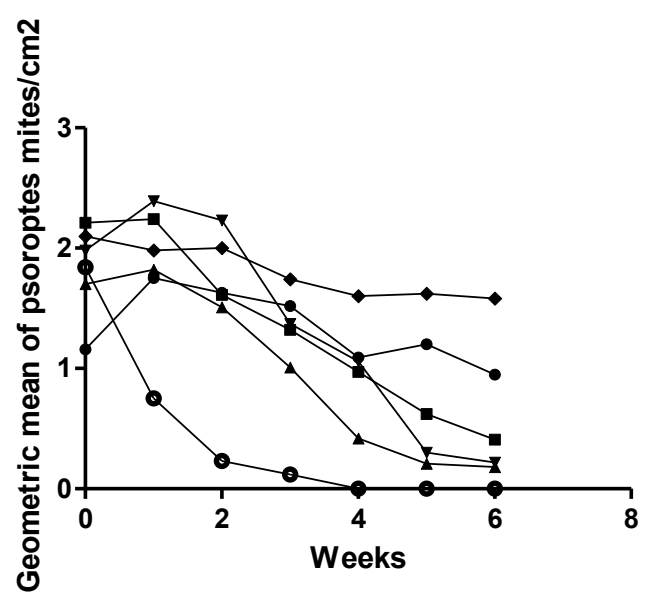

$\rightarrow$ T. africana

$\rightarrow$ P. macrophylla

$\leftarrow$ C. inophyllum

$\rightarrow$ G. mangostana

$\rightarrow$ M. myristica

$\rightarrow$ Ivermectin

Fig. 1 Weekly geometric mean of psoroptes mites $/ \mathrm{cm}^{2}$ before and after treatment with different seed oils and ivermectin

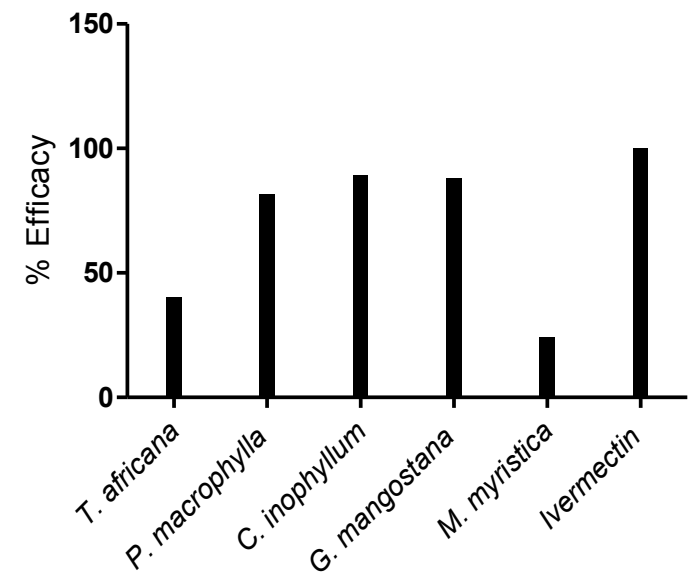

Fig. 2: Percentage efficacy of various treatments against psoroptic mites

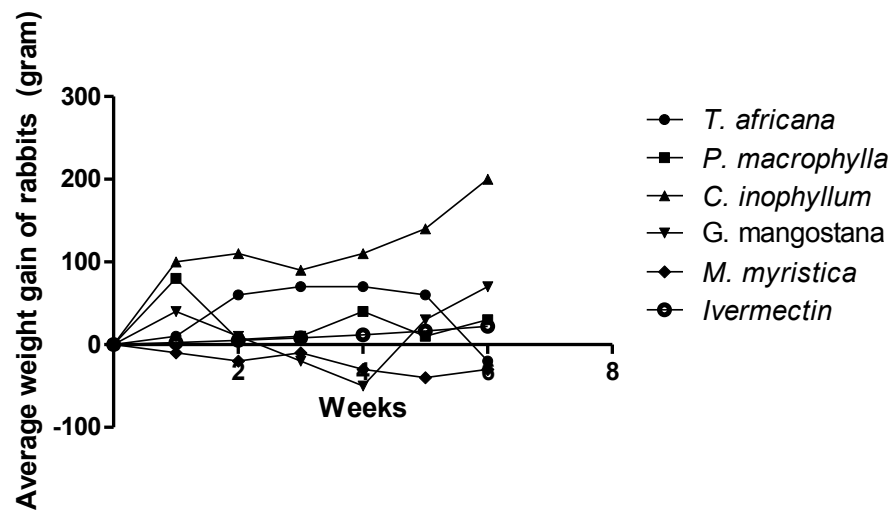

Fig. 3: Weekly average weight (gram) gain of rabbits treated with various seed oils and ivermectin 